\title{
Propagation Characteristics of Ethanol Doped Photonic Crystal Fiber
}

\author{
Pranaw Kumar ${ }^{\# 1}$, Dibakar Ghosh ${ }^{* 2}$, Saurabh Chandra ${ }^{\# 3}$, Jibendu Sekhar Roy ${ }^{* 4}$ \\ \#, *School of Electronics Engineering, KIIT University, Bhubaneswar, India \\ ${ }^{1}$ kumarpranaw9@gmail.com ,2dibakarghosh123@gmail.com , \\ 33aurav22chandra@gmail.com ,4drjsroy@rediffmail.com
}

\begin{abstract}
Six PCFs structure with different geometrical shape of holes in the cladding region and with different wafer have been investigated. Three structures A, B and C have silica as wafer where as other structure $D, E$ and $F$ have lead silicate as wafer. Structures consists of holes in the cladding region with circular and elliptical geometry. Four structures are partly filled with ethanol and other two structures have all holes filled with air. Two structures reports anomalous dispersion behaviour. Besides other structures reports zero dispersion. Almost all structures reports high birefringence along with low confinement loss. One structure shows highest nonlinearity compared to others. Besides these other propagation characteristics have also been studied.
\end{abstract}

Keyword- Photonic crystal fiber, birefringence, dispersion, effective mode area.

\section{INTRODUCTION}

This Last two decades have already being effected by the high speed transmission of light through optical fibers. However, researchers have put their efforts to make ultra-high speed propagation possible. But in such cases control over signals transmitted through the fiber is very difficult. Though conventional fiber has many merits but its limitation is designing its geometry and the contrast of the refractive index makes them less preferable in compared to photonic crystal fiber. Features like high speed with larger bandwidth, duplex transmission and good electromagnetic interface of light during its propagation makes optical fiber eligible for efficient data transmission. Again these fibres are not suitable for data transmission at higher wavelengths. Such limitations of optical fiber are overcome by the use of photonic crystal fiber. An array of microscopic channels, may be of air holes or of different refractive index, runs along its length, termed as holey fiber [1]. It consists of silica glass with periodic arrangement of these microscopic holes. Removing one or more holes from the periodic arrangements creates a defects at the centre of structure to create core. PCFs on the basis of structure can be classified as solid cores [2] and hollow cores [3]. Solid core PCF popular as Index Guided Fiber have core surrounded by holes with lower refractive index contrast in the cladding region. Light gets propagated by modified Total Internal Reflection (m-TIR) guiding mechanism in such fibers [4]. Again hollow core fibers have core surrounded by holes with greater refractive index in the cladding region. PCFs have made a promising approach to handle the higher bit transmissions. It also offers wide flexibility in designing its structures. Flexibility in pitch factor, dimension of holes in the cladding region and its sizes too [5-7]. PCFs with such flexibility results with unique features like birefringence [8], dispersion [9], endlessly single mode propagation [10] and low loss [11]. Birefringences [12-13], a highly desirable property describes the maintenance of input polarization state in fiber. It depends on both direction of polarization and propagation of light transmitted inside the fiber. Light as an effect of birefringence gets splitted into two orthogonal polarization components with different refractive indices. PCFs with high birefringence have been reported till now. Besides researchers have made various effort to report highly birefringent fibers. Non-linear effects in fibers limits its data carrying capacity. It also results broadening of the frequency of the light propagating inside the fiber. Non-linearity of a fiber is inversely proportional to the effective mode area. Effective mode area increases with operating wavelength [14]. Chromatic dispersion in optical fiber has been one of the major limitations of fibers. Researchers have put their efforts to minimize dispersion. However fibers with zero dispersion and large nonlinearity are widely applicable in optical parametric oscillator, signal switcher and multi wavelength laser. Again almost flattened dispersion observed in fibers is also an important issue. Splitting or broadening of optical pulse during its propagation inside fiber is caused by dispersion [15]. These dispersion properties are affected by the refractive index contrast between core and cladding region. Variation in diameter of holes in the cladding region, pitch factor and the arrangement of holes in the cladding region are the dispersion controlling parameters of fibers. Dispersion observed in fibers are of two types:- Material dispersion and waveguide dispersion. Zero dispersion fibers, ultra flattened dispersion and negative dispersion fiber has been reported so far [16-17]. Various other PCFs structures to minimize dispersion has also been simulated. Highly birefringent fibers with low effective mode area and zero dispersion are widely applicable for non-linear applications. Moreover confined optical field with small effective mode area and high non-linearity can also be obtained. These fibers are used in various optical devices. Partial incident energy leaks out of core into the core-cladding boundary through holes present in the cladding region facing core. Such kind of losses are termed as leakage loss or 
confinement loss. These losses can be reduced by increasing the contrast of refractive index between core and cladding region. Researchers have made efforts to minimize such losses [18]. Endlessly single mode propagation offered by PCF makes them much preferable for transmission over conventional optical fiber in optical communication system [19].

Six PCFs structure with different geometrical shape of holes in the cladding region have been investigated. Structures A, B and C have silica as wafer where as structure D, E and F have lead silicate as wafer. Structures consists of holes in the cladding region with circular and elliptical geometry. Two structures have all holes filled with air. Other structures have ethanol filled in either circular or elliptical holes. Intention is to study the propagation characteristics of light in structures with different materials as wafer and also with different geometry. Out of the investigated six structures, two structures reports anomalous dispersion behaviour. Besides other structures reports zero dispersion. Almost all structures reports high birefringence along with low confinement loss.

\section{THEORY AND DESIGN}

We have simulated three structures with lead silicate as wafer and three structures have silica as wafer. Lead silicate has refractive index 1.80 and silica has 1.45 . Structure A have all the holes filled with air. Structures B have circular holes filled with air and elliptical holes filled with ethanol. Structure C has circular holes filled with ethanol and elliptical holes filled with air. Similar to Structure A, B and C, structure D, E and F have same dimension except wafer with lead silicate instead of silica. Intention is to study and compare the behaviour of light in process of different material with that of air. Also the effect of variation in geometry of holes in the cladding region is investigated. Transverse section of the designed PCFs has been shown in Fig. 1 (a). Designed consists of seven ring of holes in the cladding region. Structure is chosen such that it has exterior three rings with holes of circular dimension. Inner most four rings have holes with elliptical geometry. Both elliptical and circular geometry have equal area.

The birefringence of the fiber is often measured as the difference of two polarization modes propagation in the fiber [20].

$$
B=\left|R_{e}\left(n_{\text {eff }}{ }^{x}\right)-R_{e}\left(n_{e f f}{ }^{y}\right)\right|
$$

Birefringence can also be obtained from the beat length. Asymmetric core and effective index contrast between orthogonal polarized modes are two important parameter considered to reactive birefringence of a fiber. Asymmetrical core can be achieved by varying the diameter of holes near core. The same can be achieved by altering the shape of the holes or a defect in the centre of the core can be introduced in this regard.

Material dispersion and waveguide dispersion together contributes to chromatic dispersion. It can be controlled by varying diameter of holes facing core in the cladding region, and by varying number of holes in the cladding region. Moreover dimension of holes in the cladding region also effects dispersion. It can be calculated as [21]

$$
D_{w}=\frac{-\lambda}{c} \frac{d^{2} R_{e}\left(n_{e f f}\right)}{d \lambda^{2}}
$$

Where $\lambda$ represents wavelength and $R_{e}\left(n_{\text {eff }}\right)$ is real part of effective refractive index.

Lower effective mode area results high non-linearity. Area occupied by the fundamental mode inside the fiber is termed as effective mode area and is obtained by [22]

$$
A_{\text {eff }}=\frac{\left[\iint|E(x, y) d x d y|^{2}\right]^{2}}{\iint|E(x, y) d x d y|^{4}}
$$

Effective mode area of a fiber is inversely proportional to its Non-linearity. It can be determined by using [22]:

$$
\gamma=\frac{n_{2} \omega}{c A_{\text {eff }}}=\frac{2 \pi n_{2}}{\lambda A_{\text {eff }}}
$$

$$
n_{2} \text { is the non-linear refractive index coefficient }\left(3.01 X 10^{20} \mathrm{~m}^{2} / W\right. \text { for Silica). }
$$

Increase in the number of holes filled with air results the mode to be more confined inside the core. It results reduction in leakage loss. However as the modes spread out of the core with increase in wavelength, it also results increase in loss [22].

$$
L_{c}=8.686 k_{o} I_{m}\left[n_{e f f}\right] d B / m
$$


Endlessly single mode to one of the unique feature of photonic crystal fibre. $V_{\text {eff }}$ helps in determining in single modeness of any fibre. It can be calculated as [23]

$$
V_{\text {eff }}=2 \pi \frac{\Lambda}{\lambda} \sqrt{n_{\text {core }}^{2}-n_{\text {eff }}^{2}}
$$

Where $\Lambda$ is the hole pitch, $\lambda$ is the wavelength in vacuum, the $n_{\text {core }}$ is the refractive index of core which is Silica and $n_{\text {eff }}$ is the effective refractive index.

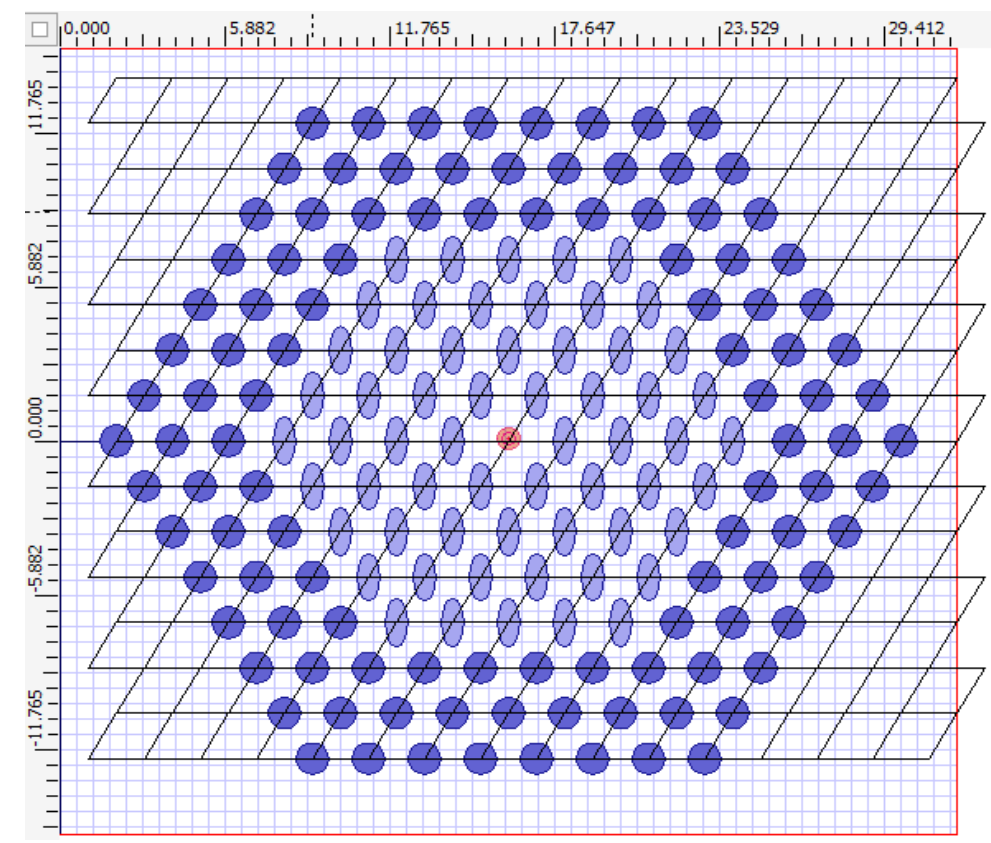

Fig. 1 (a) Designed PCF structure.

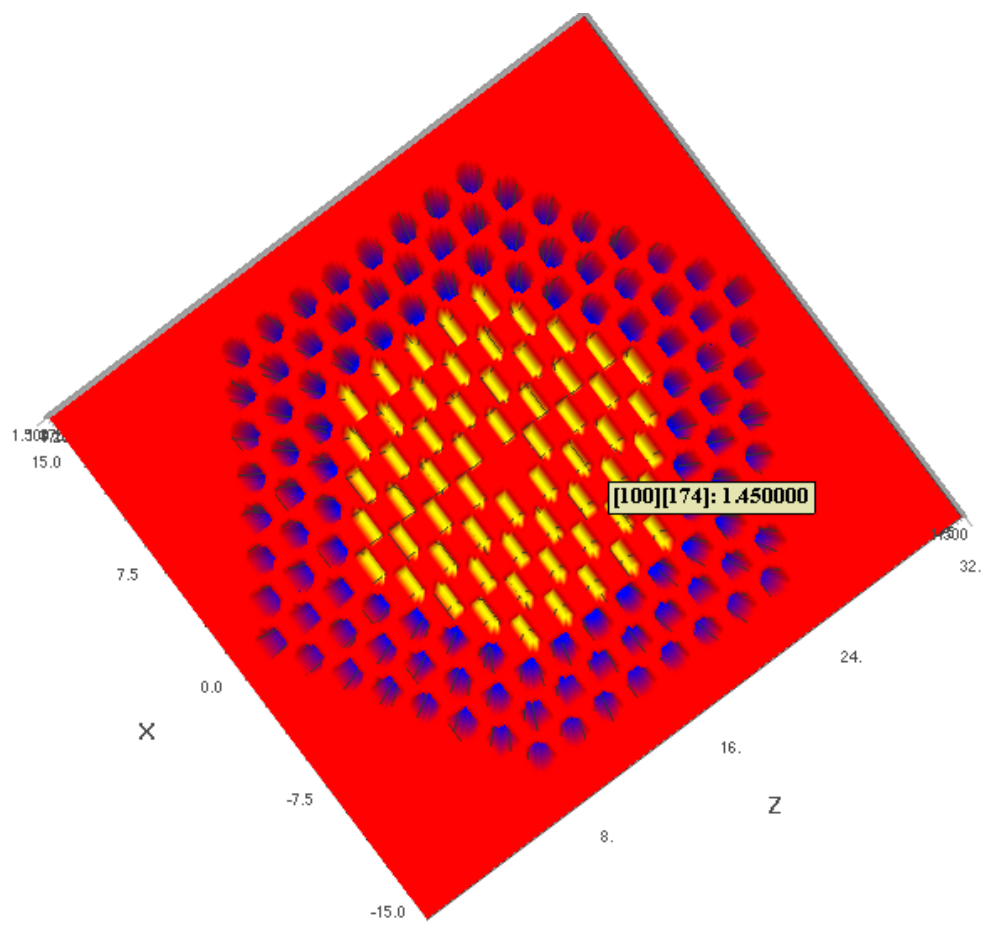

Fig. 1 (b) Designed PCF structure. 
Table 1. Summary of Structure Simulated:

\begin{tabular}{|l|l|l|}
\hline Structure & Wafer/ Refractive Index & Description of Structure \\
\hline A & Silica/ 1.45 & $\begin{array}{l}\text { Both Circular and Elliptical holes filled } \\
\text { with air. }\end{array}$ \\
\hline B & Silica/ 1.45 & $\begin{array}{l}\text { Circular air holes and elliptical holes filled } \\
\text { with ethanol (Refractive Index 1.36). }\end{array}$ \\
\hline C & Silica/ 1.45 & $\begin{array}{l}\text { Circular holes filled with Ethanol and } \\
\text { Elliptical air holes. }\end{array}$ \\
\hline D & Lead Silicate/ 1.80 & $\begin{array}{l}\text { Both Circular and Elliptical holes filled } \\
\text { with air. }\end{array}$ \\
\hline E & Lead Silicate/ 1.80 & $\begin{array}{l}\text { Circular air holes and elliptical holes filled } \\
\text { with ethanol (Refractive Index 1.36). }\end{array}$ \\
\hline F & Lead Silicate/ 1.80 & $\begin{array}{l}\text { Circular holes filled with Ethanol and } \\
\text { Elliptical air holes. }\end{array}$ \\
\hline
\end{tabular}

\section{SIMULATION AND RESULTS}

All A full vector module of Opti-FDTD software have been used for simulation. TBC (transparent boundary condition) surround the core-cladding region and it has been consider to report optimized result. Wafer is made of silica with refractive index 1.45 and Lead silicate with refractive index 1.80. Structure F having lead silicate filled holes with elliptical geometry reports the highest birefringence in comparison to rest all strutures. Structure A reports birefringence of the order $10^{-3}$, where as other structures reports birefringence of the order $10^{-2}$.

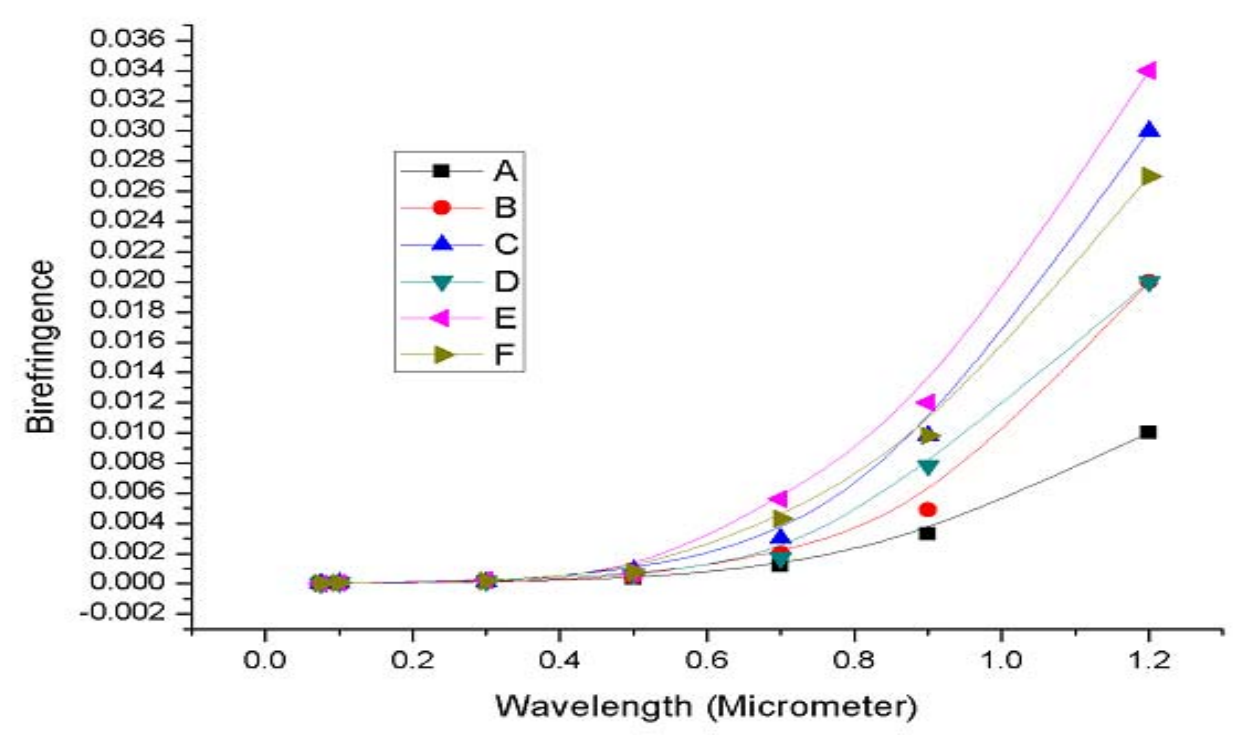

Fig. 2 (a) Birefringence behavior.

Structure A, C, D and E reports zero dispersion at first and second optical windows. Moreover structure A and E shows ultra flattened dispersion. However structure $\mathrm{C}$ reports negative dispersion in the visible range. Even at a wavelength of $1.2 \mu \mathrm{m}$, obtained dispersion by structure C is nearly $-170 \mathrm{ps} / \mathrm{nm}-\mathrm{Km}$. On the other hand, Structure $\mathrm{B}$ and F shows anomalous behaviour. Dispersion observed by both structures is below $20 \mathrm{ps} / \mathrm{nm}-\mathrm{km}$. 


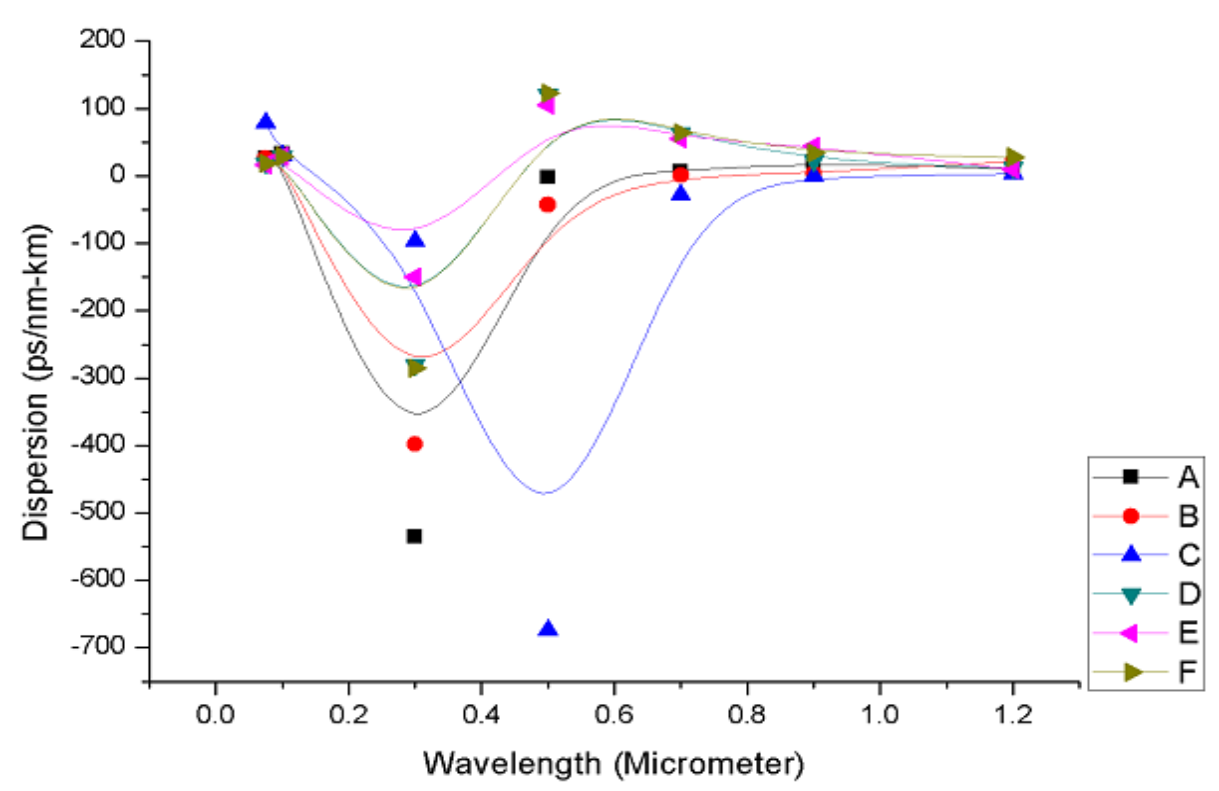

Fig. 2 (b) Dispersion behavior.

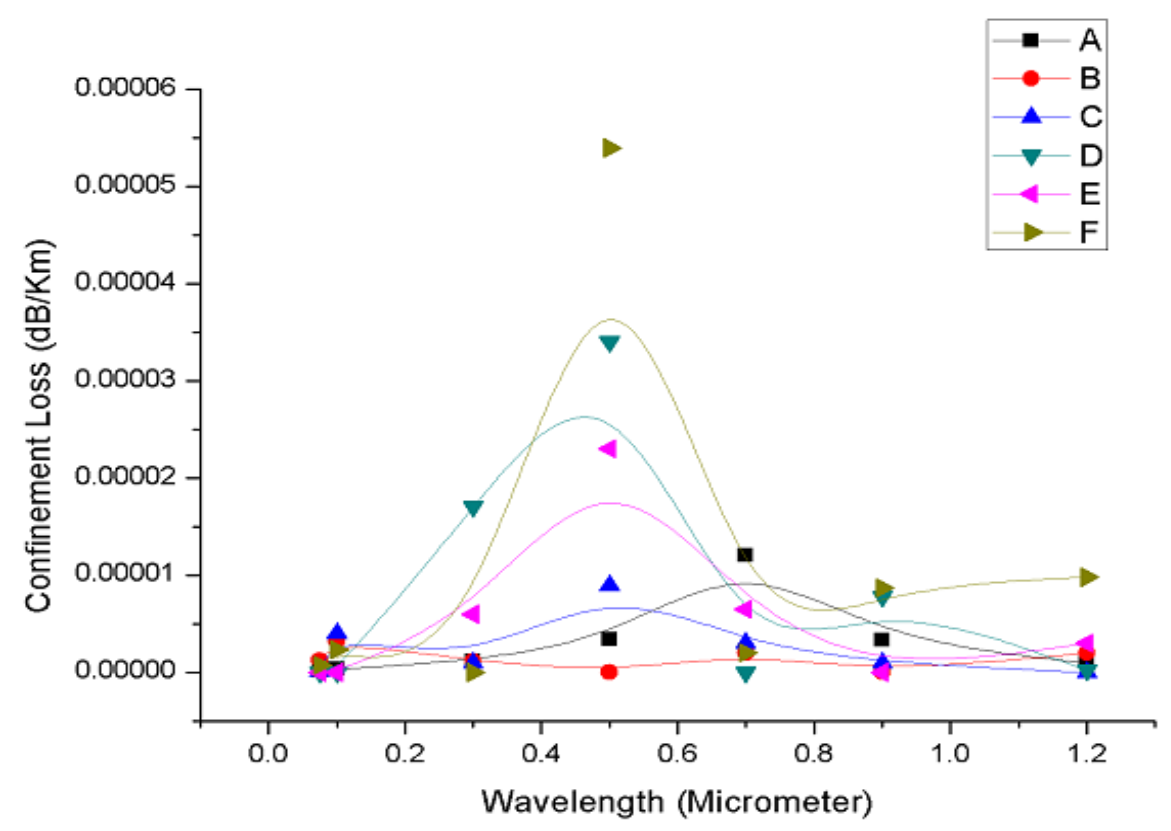

Fig. 2 (c) Confinement loss behavior

Structure A, C, D and E reports very low loss. Loss for these sstructures is of the order $10^{-6}$. Structure B and F reports comparatively higher loss. 


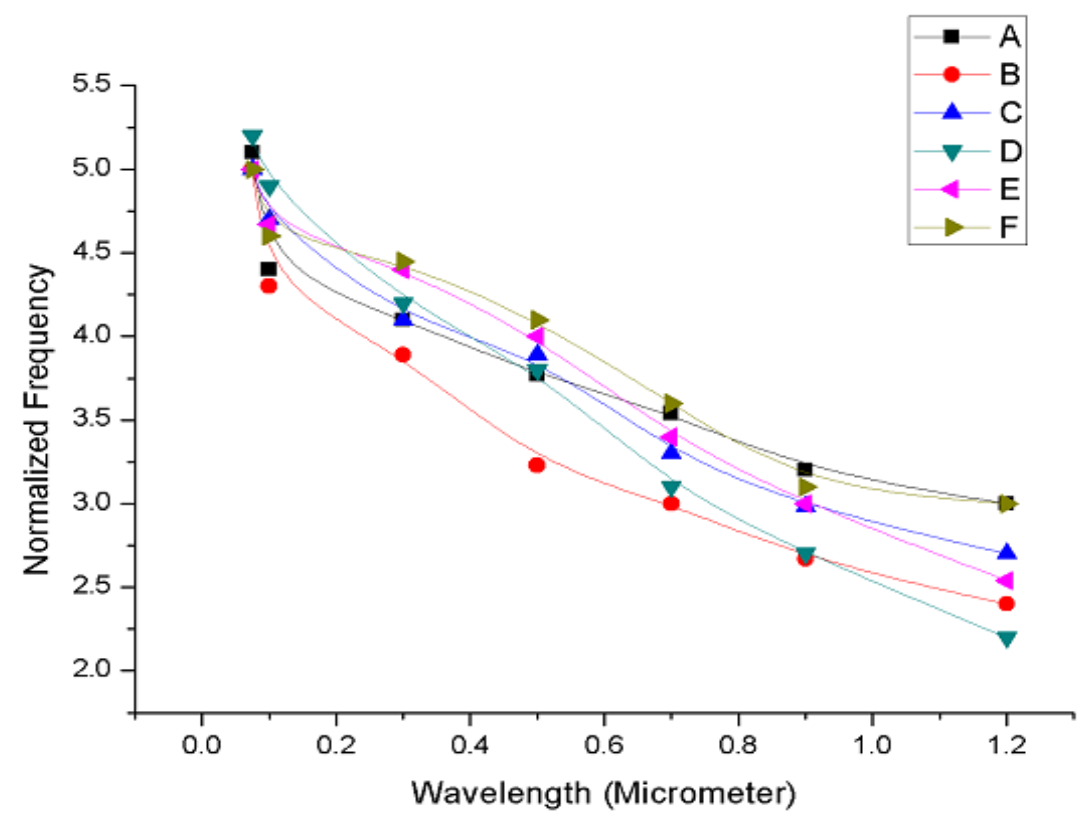

Fig. 2 (d) Normalized frequency

Simulated structures reports single mode propagation. Normalized frequency lesser than 4.1. assures single mode propagation for these structures.

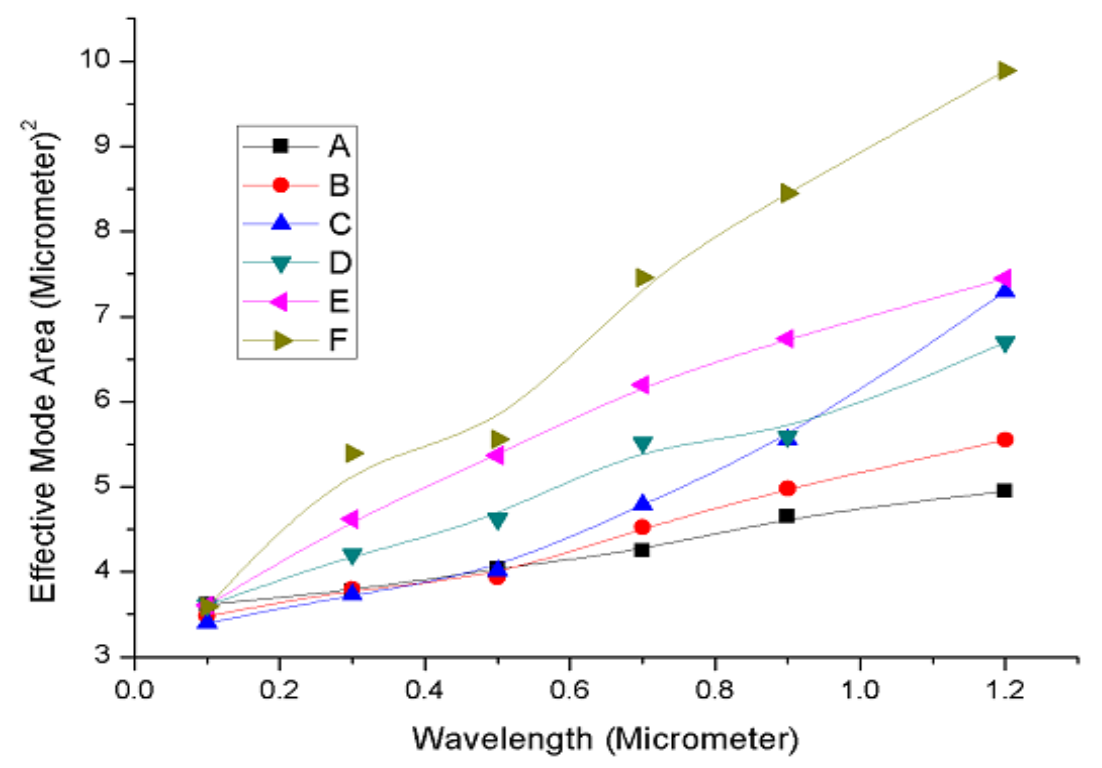

Fig. 2 (e) Effective mode area.

Effective mode area obtained for Structure F is the highest than other structures. However other structures also have high effective mode areas. Structure A has the lowest effective mode area. Thus Structure offers comparatively less non-linearity than structure A. 


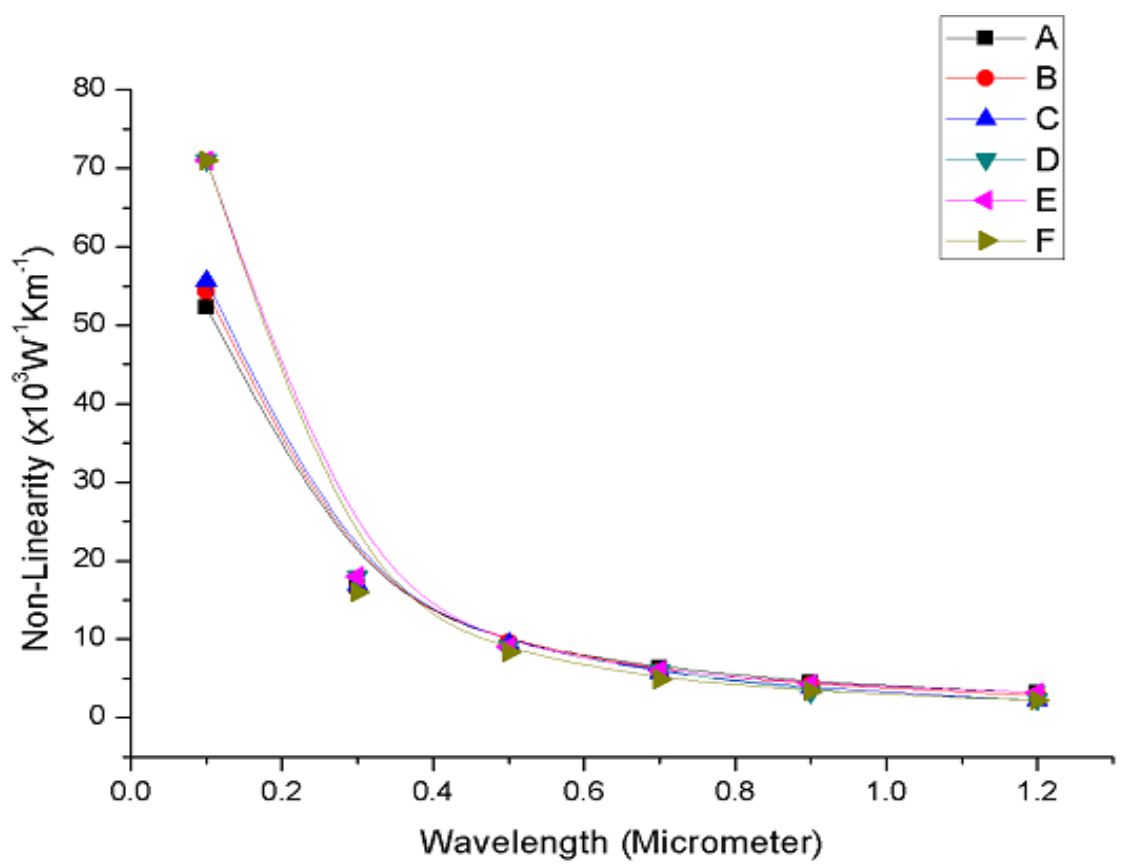

Fig. 2 (f) Non linearity behavior

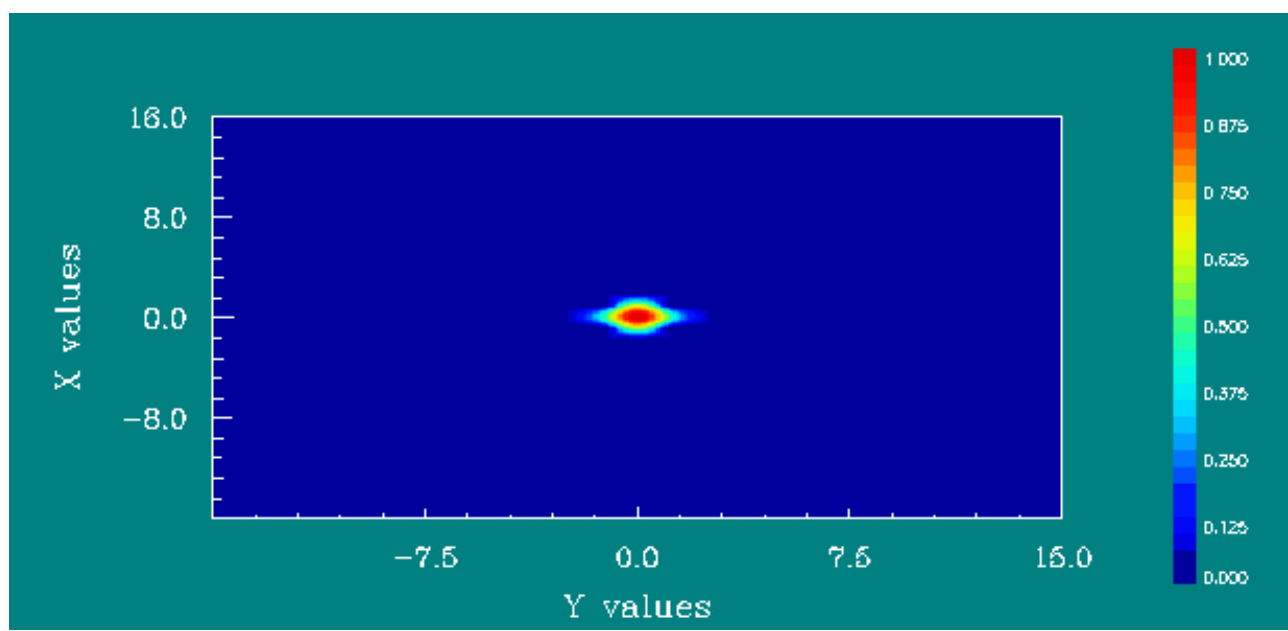

Fig. 2 (g) Fundamental mode.

Table 2. Comparison of results of all Structures.

\begin{tabular}{|l|l|l|l|l|l|l|}
\hline PARAMETER & Structure A & Structure B & Structure C & Structure D & Structure E & Structure $\mathbf{F}$ \\
\hline Birefringence & $10^{-3}$ & $10^{-2}$ & $10^{-2}$ & $10^{-3}$ & $10^{-2}$ & $10^{-2}$ \\
\hline Dispersion & ZERO & Anomalous & ZERO & ZERO & ZERO & Anomalous \\
\hline $\begin{array}{l}\text { Confinement } \\
\text { Loss }\end{array}$ & $10^{-5}$ & $10^{-5}$ & $10^{-5}$ & $10^{-5}$ & $10^{-5}$ & $10^{-5}$ \\
\hline $\begin{array}{l}\text { Normalized } \\
\text { Frequency }\end{array}$ & $V_{\text {eff }} \leq 4.1$ & $V_{\text {eff }} \leq 4.1$ & $V_{\text {eff }} \leq 4.1$ & $V_{\text {eff }} \leq 4.1$ & $V_{\text {eff }} \leq 4.1$ & $V_{\text {eff }} \leq 4.1$ \\
\hline $\begin{array}{l}\text { Effective } \\
\text { Mode Area }\end{array}$ & $\begin{array}{l}4.95(\mu \mathrm{m})^{2} \\
1.2 \mu \mathrm{m}\end{array}$ & $\begin{array}{l}5.55(\mu \mathrm{m})^{2} \\
\text { at } 1.2 \mu \mathrm{m}\end{array}$ & $\begin{array}{l}7.29(\mu \mathrm{m})^{2} \\
\text { at } 1.2 \mu \mathrm{m}\end{array}$ & $\begin{array}{l}6.7(\mu \mathrm{m})^{2} \text { at } \\
1.2 \mu \mathrm{m}\end{array}$ & $\begin{array}{l}7.45(\mu \mathrm{m})^{2} \\
\text { at } 1.2 \mu \mathrm{m}\end{array}$ & $\begin{array}{l}9.89(\mu \mathrm{m})^{2} \\
\text { at } 1.2 \mu \mathrm{m}\end{array}$ \\
\hline Nonlinearity & $\begin{array}{l}3180\left(\mathrm{~W}^{-}\right. \\
\left.{ }^{1} \mathrm{Km}^{-1}\right)\end{array}$ & $\begin{array}{l}2839\left(\mathrm{~W}^{-}\right. \\
\left.{ }^{1} \mathrm{Km}^{-1}\right)\end{array}$ & $\begin{array}{l}2170\left(\mathrm{~W}^{-}\right. \\
\left.{ }^{1} \mathrm{Km}^{-1}\right)\end{array}$ & $\begin{array}{l}2300\left(\mathrm{~W}^{-}\right. \\
\left.{ }^{1} \mathrm{Km}^{-1}\right)\end{array}$ & $\begin{array}{l}3190\left(\mathrm{~W}^{-}\right. \\
\left.{ }^{1} \mathrm{Km}^{-1}\right)\end{array}$ & $\begin{array}{l}2170\left(\mathrm{~W}^{-}\right. \\
\left.{ }^{1} \mathrm{Km}^{-1}\right)\end{array}$ \\
\hline
\end{tabular}




\section{IV.CONCLUSION}

Thus, six PCFs structure with different geometrical shape of holes in the cladding region have been investigated. Structures A, B and C have silica as wafer where as structure D, E and F have lead silicate as wafer. Structures consists of holes in the cladding region with circular and elliptical geometry. Two structures have all holes filled with air. Other structures have ethanol filled once in circular and next in elliptical holes. Intention is to study the propagation characteristics of light in structures with different materials as wafer and with holes of different geometry. Two structures reports anomalous dispersion behaviour. Besides other structures reports zero dispersion. Almost all structures reports high birefringence along with low confinement loss. Hence all the structure is considered to be good for optical communication, optical devices, optical sensor and other linear as well non-linear application.

\section{REFERENCES}

[1] P. St. J. Russell, “Photonic-Crystal Fibers,” J. Lightwave Technol, vol. 24, pp. 4729-4749, 2006.

[2] Takashi Matsui, T. Sakamoto, K. Tsujikawa, S. Tomita, and M. Tsubokawa, "Single mode photonic crystal fiber design with ultra range effective area and low bending loss for ultra high-speed WDM transmission”, Journal of Lightwave Technology, vol. 29, no. 4, February 15, 2011.

[3] Cregan, R.F., Mangan, B.J., Knight, J.C., Birks, T.A., Russell, P.S.J., Roberts, P.J. and Allan, D.C. (1999) "Single mode photonic band gap guidance of light in air", Science, vol. 285, pp.1537-1539, 1999.

[4] N. H. Hai, Y. Namihiray, S. F. Kaijage, T.Kinjo, F. Begum, S. M. A. Razzak and N. Zou, "Multiple defect-core hexagonal photonic crystal fiber with flattened dispersion and polarization maintaining properties,” Opt. Review, vol. 15, pp. 31-37, 2008.

[5] Pranaw Kumar, P. Das, "Photonic crystal fiber with anomalous dispersion beahviour and high birefringence", ICATCCT, Devangere, October, 2015.

[6] X. Freng et al., "Single-mode tellurite glass holey fibre with extremely large mode area for infrared nonlinear applications", Opt. Express 16 (18),13651, 2008.

[7] K. Kaneshima. Y. Namihira, N. Zou, H. Higa, and Y. Nagata, "Numerical investigation of octagonal photonic crystal fibers with strong confinement field,” IEICE Trans. Electron., vol. E89-C, no. 6, pp. 830-837, 2006.

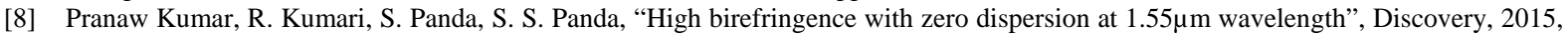
42(193), pp.113-116, 2015.

[9] K. Saitoh, M. Koshiba, "Highly nonlinear dispersion-flattened photonic crystal fiber for supercontinuum generation in a telecommunication window", Opt. Express , vol. 12, pp. 2027-2032, 2004.

[10] T.A. Birks, J.C.Knight, P.St.J. Russell, “Endlessly single-mode photonic crystal fiber”, Opt. Lett. 22, pp. 961-963, 1997.

[11] D. Ferrarini, L. Vincetti, M. Zoboli, “Leakage properties of photonic crystal fibers”, Opt. Express, 10, pp. 1314-1319, 2002.

[12] Pranaw Kumar, M. Senapati, S.S. Panda, “Applications of photonic crystal fibers for high speed transmission and optical devices”, ISCO, Coimbatore, January, 2016.

[13] J. Wang, C. Jiang, W. Hu and M. Gao,”Properties of index guided PCF with air core,” Optics and Laser Tech., 39, pp. 317-321, 2006.

[14] X. Freng et al., "Single-mode tellurite glass holey fibre with extremely large mode area for infrared nonlinear applications", Opt. Express 16, vol.18, pp.13651-59, 2008.

[15] J. Liao, J. Sun, M.Du, and Y.Qin, “Highly nonlinear dispersion-flattened slotted spiral photonic crystal fibers”, IEEE Photon.Technol. Lett., vol. 26, no. 4, pp. 380-383, 2014.

[16] K. H. Kim, H. K. Lee, S. Y. Park and El-Hang Lee, "Calculation of dispersion and nonlinear effect limited maximum TDM and FDM bit rates of transform-limited pulses in single mode optical fiber,” J.Lightw.Technol, vol. 13, no. 8, pp. 1597-1605, August 1995.

[17] S. M. A. Razzak, Y. Namihira, F. Begum, S. Kaijage, N. H. Hai, and N. Zou, "Design of a decagonal photonic crystal fiber with ultraflattened chromatic dispersion ,” IEICE Trans. Electron., vol. E90-C, no. 11, pp. 2141-2145, Nov. 2007.

[18] M. Uthman, B.M.A. Rahman, N. Kejalakshmy, A. Agarwal, K.T.V. Grattan, ”Design and characterization of low-loss photonic crystal fiber, "IEEE photonics J. ,vol. 4, no. 6, pp. 2315-2325, Dec. 2012.

[19] Pranaw Kumar, P. Das, A. K. Meher, "S-shaped and U-shaped photonic crytal fiber with zero dispersion”, IJAER, Spl.issue, vol. 10, no. 20, pp. 18666-18669, October, 2015.

[20] G. P. Agrawal, "Nonlinear Fiber Optics”, (Academic Press, 2011).

[21] John D. Joannopoulos, Steven G. Johnson, Josgua N. Winn, Robert D. Mede, "Photonic crystal fiber: Molding the flow of light", $2^{\text {nd }}$ edition, Priceton University Press, 2008.

[22] Ajoy Ghatak, K. Thyagarajan, "Introduction to Fiber optics”, $1^{\text {st }}$ South Asian Edition 1999

\section{AUTHOR PROFILE}

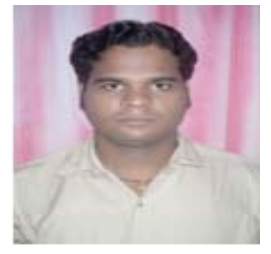

Pranaw Kumar working as an Assistant Professor in School of Electronics Engineering, KIIT University, Bhubaneswar. He received his Master of Technology in Communication Engineering in 2012 from MNIT Jaipur. He is a member of OSA, SPIE and Life-member of Indian Science Congress Association. He is also an IEEE student member. His area of research includes Photonic Crystal Fibres, Optical Communication, Microstrip Antenna, Communication and Signal Processing. Email- kumarpranaw9@gmail.com

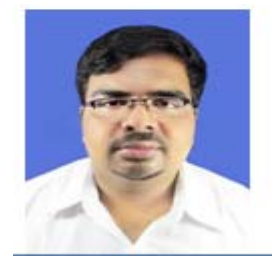

Dibakar Ghosh from Dibrugarh, Assam has received his B.Tech degree from KIIT University, Bhubaneswar in April 2017. His area of interest included Photonic Crystal Fiber. Email-dibakarghosh123@gmail.com 


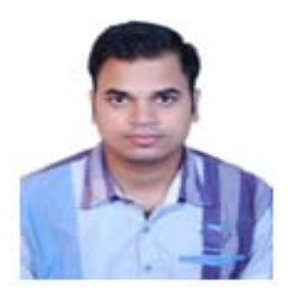

Saurabh Chandra from Korba, Chhattisgarh received his B.E. degree in Electronics and Telecommunication Engineering from Christian College of Engineering and Technology, Bhilai affiliated to Chhattisgarh Swami Vivekanand Technical University, Bhilai in 2014. Recently he has been awarded Master of Technology in Communication System Engineering from KIIT University, Bhubaneswar. His area of interest includes Microstrip Antenna and Photonic Crystal Fiber. Email- saurav22chandra@gmail.com

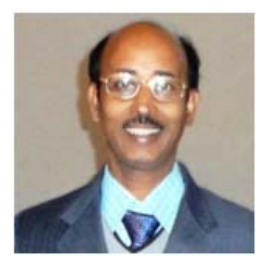

Dr. Jibendu Sekhar Roy is a professor in the School of Electronics Engineering, KIIT University, Bhubaneswar, Odisha, India. From 1998 to 2009, he was lecturer, reader and professor in the ECE department of Birla Institute of Technology, Mesra, Ranchi, India. He has received Ph. D. degree from the Department of Electronics \& Telecommunication Engineering, Jadavpur University, Calcutta. From 1991 to 1993, he was a post-doctoral research associate of CNRS, Govt. of France in IRCOM, University of Limoges, France. From 1994 to 1998, he was a research associate of CSIR in ETCE department, Jadavpur University, Calcutta. His research interest includes microwave and millimeterwave antennas for wireless communication, optimization of thinned array antenna, smart antennas, channel assignment \& MIMO-OFDM algorithms, cognitive radio. He has completed several government sponsored projects. Dr. Roy has published about 200 papers in international journals and symposia. Dr. Roy has supervised several Ph. D. theses. He has presented Invited lectures/research papers in workshops and symposia in various Institutes in India and other countries, like, France, USA, Indonesia, Italy, Denmark, Czech Republic and South Korea. He has been awarded Senior Associate ship of ICTP (UNESCO), Trieste, Italy in 2008. He is a Lifemember of ISTE (India) and Life-member of Indian Science Congress Association and member of IAENG. Dr. Roy is regular reviewer of many international journals. The name of Dr J. S. Roy has been listed in 2012 Marquis World Who's Who. Email-drjsroy@rediffmail.com 